\title{
Possibilities of using sentinel-2 satellite data to estimate crop cover and LAl of winter wheat at different stages of development
}

\author{
Feddy Mullo ${ }^{1, *}$, Elena Prudnikova ${ }^{2,3}$ \\ ${ }^{1}$ Peoples' Friendship University of Russia (RUDN University), Faculty of Ecology, 6 Miklukho- \\ Maklaya St, Moscow, 117198, Russian Federation \\ ${ }^{2}$ Peoples' Friendship University of Russia (RUDN University), Agroengineering Department, \\ Agrarian-Technological Institute, Faculty of Ecology, 6 Miklukho-Maklaya St, Moscow, 117198, \\ Russian Federation \\ ${ }^{3}$ V.V. Dokuchaev Soil Science Institute, Pyzhevskiy pereulok, 7, Moscow, 119017, Russia
}

\begin{abstract}
The study was conducted on a test plot located in the Yasnogorodsky district of the Tula Region; With a camera with fisheye lens photographs were taken at different points of the plot, each point with a geographical reference. Subsequently, the possible relationship between the information extracted from the classification of the photographs using the CAN-EYE software (LAI, percentage of vegetation) and the vegetation indices (Ratio, NDVI, SAVI and EVI) calculated with spectral values obtained from the different channels of Sentinel-2 (B2, B3, B4, B5, B6, B7, B8, B8a) were evaluated. Finally, best regression models obtained for each phase of the winter wheat development were used to create the maps of LAI and percentage of vegetation. According to our results, Sentinel-2 can be successfully used to map LAI in the studied region at the shooting stage of winter wheat development with accuracy of $85 \%$. At other stages and for percentage of vegetation the accuracy of the models was below $50 \%$.
\end{abstract}

\section{Introduction}

Remote sensing of the Earth from space using digital methods and image processing techniques is widely used to monitor environmental changes; and in recent decades it has been widely used in agriculture (Martinez, 2005). In vegetation studies actual information on canopy chlorophyll content, in addition to properties like leaf area index, biomass and fraction of absorbed photosynthetically active radiation, is important in understanding plant functioning and status (Clevers and Gitelson, 2013).

Photosynthesis is one of the key processes in plants that is responsible for the energy and carbon balance. Actual chlorophyll estimates are important for applications such as precision agriculture, since chlorophyll is the main plant constituent determining the reflectance in the visible region of the spectrum, optical remote sensing techniques have great potential in providing information on canopy chlorophyll.

\footnotetext{
* Corresponding author: mfreddy.28fm@gmail.com
} 
Leaf area index (LAI) is a dimensionless variable defined by Watson (1947) as the area on one side of the photosynthetic leaf tissue per unit area of soil. LAI is a key biophysical variable fundamental in natural vegetation and agricultural land monitoring and modelling studies. LAI is the main determinant of the processes of photosynthesis and the evapotranspiration of crops.

Satellite-derived LAI maps have been used in many earth observation studies including evapotranspiration (Allen et al., 1998 and Duchemin et al., 2006), net ecosystem production (Barr, 2004) and rainfall interception by forests (Dietz et al., 2006), as well as in yield estimation and in downstream services for crop monitoring (Busetto, 2017). In the last few years, non-destructive methods have been developed to determine the percentage of vegetation cover and LAI. There are few studies that validate LAI estimates in crops with data taken in situ (Sandmann, 2013).

Sentinel-2 provides images with high spatial, spectral and temporal resolution. It covers the visible and near-infrared (VNIR) and the shortwave-infrared (SWIR) spectral region in 13 bands, incorporating two new spectral bands in the so-called red-edge region, which are very important for retrieval of chlorophyll content (Delegido et al., 2011, Gitelson et al., 2005). Sentinel-2 has, an increased sensitivity towards LAIgreen, while the shortwave infrared bands are sensitive to cellulose and lignin (dry matter) absorption (Delegido et al., 2015).

Thus, the objective of the study was to analyze the possibilities of using Sentinel-2 data to assess crop cover and LAI of winter wheat at different stages of development on the basis of ground-truth measurements.

\section{Research methods}

Test plot is located in Yasnogorodsky district of the Tula Region. During the year 2018 three field trips were made to the test plot: on 27.04.2018 (tillering stage), 1.06.2018 (shooting stage), 6.07.2018 (milky ripeness). During each trip photos of crops with a fish-eye lens camera were made: at 22 points at tillering stage, at 14 points at shooting and milky ripeness stage. At each point 5 photos were taken.

For the analysis of the photos, we used CAN_EYE software. As a result, for each sample point at each stage of development we determined percentage of vegetation (percentage of surface covered by vegetation) and LAI.

The EarthExplorer portal of the Geological Survey of the United States (USGS) was used to download Sentinel-2 images corresponding to the dates closest to the field trips (Table 1). For each of the development phases, Level-1C images were obtained: for the first stage - for April 27, 2018; for the second stage - June 1, for the last stage - July 6. The atmospheric correction of the images was performed with the Sen2Cor tool using the Sentinel Application Platform (SNAP).

Table 1. Bands of Sentinel-2 used in the study (Source: Sentinel Online*)

\begin{tabular}{|l|c|c|}
\hline \multicolumn{1}{|c|}{ Bands } & Resolution (m) & Central wavelength (nm) \\
\hline B2 - Blue & 10 & 490 \\
\hline B3 - Green & 10 & 560 \\
\hline B4 - Red & 10 & 665 \\
\hline B5 - Vegetation red edge & 20 & 705 \\
\hline B6 - Vegetation red edge & 20 & 740 \\
\hline B7 - Vegetation red edge & 20 & 783 \\
\hline B8 - NIR & 10 & 842 \\
\hline B8a - Narrow NIR & 20 & 865 \\
\hline
\end{tabular}

*https://earth.esa.int/web/sentinel/user-guides/sentinel-2- msi/resolutions/spatial 
With the spectral values obtained from the different bands, we proceeded to calculate vegetatation indices such as: Ratio $\left(\mathrm{R}_{\mathrm{NIR}} / \mathrm{R}_{\mathrm{red}}\right)$, NDVI ((NIR-Rred) / (NIR + Rred)), SAVI $\left(\left(\mathrm{R}_{\mathrm{NIR}}-\mathrm{R}_{\mathrm{red}}\right)(1+\mathrm{L}) /\left(\mathrm{R}_{\mathrm{NIR}}+\mathrm{R}_{\text {red }}+\mathrm{L}\right)\right)$ and EVI $\left(\left(2.5\left(\mathrm{R}_{\mathrm{NIR}}-\mathrm{R}_{\text {red }}\right) /\left(\mathrm{R}_{\mathrm{NIR}}+6 \mathrm{R}_{\text {red }}-7.5 \mathrm{R}_{\text {blue }}+\right.\right.\right.$ 1)) These indices are widely used to determine the values of biomass, LAI and plant cover (Jerry et al., 2010). 25 (referred to as R1 to R25) possible combinations were obtained for the RATIO index, for Red NDVI - 21 combinations (referred to as RED1 to RED21), assessment of crop phenology during the growing season has been assessed using a comparison of the NDVI with a visible atmospherically resistant index expressed either as Green NDVI ( $\left(\mathrm{R}_{\mathrm{NIR}}-\mathrm{R}_{\text {green }}\right)$ / $\left(\mathrm{R}_{\mathrm{NIR}}+\mathrm{R}_{\text {green }}\right)$ ) (referred to as Green1 to Green5) or Red Edge $\operatorname{NDVI}\left(\left(\mathrm{R}_{\mathrm{NIR}}-\mathrm{R}_{\text {red edge }}\right) /\left(\mathrm{R}_{\mathrm{NIR}}+\mathrm{R}_{\text {red edge }}\right)\right.$ ) (referred to as Edge1 to Edge4) (Vina et al., 2004), and SAVI and EVI- 5 combinations respectively.

Then, regression analysis was performed in SPSS to determine the relationships between the parameters obtained from the analysis of photos (LAI_3rings, LAI_4rings, LAI_5rings, percentage of vegetation) and vegetation indices, calculated from Sentinel-2. The best models with highest adjusted $\mathrm{R}^{2}$ and statistically significant variables were used in ILWIS 3.3 Academic to create maps of LAI and percentage of vegetation for each development stage of winter wheat.

\section{Results and Discussion.}

Tillering stage: For the tested regression models for percentage of vegetation, the highest accuracy was below $35 \%$ (adjusted $\mathrm{R}^{2}=0.337$ ) The model includes R13, RED13, EVI2 and EVI5 as predictor variables (Fig. 1 a).

The best model was obtained for LAI_5rings and it explaines $36.7 \%$ (adjusted $\mathrm{R}^{2}=0.367$ ) of the changes of the dependent variable. It includes the following vegetation indicies: R12, R13, R24 and RED21 (Fig. 1 b).

Shooting stage: Best regression model for vegetation percentage explaines $43.8 \%$ of the changes (adjusted $\mathrm{R}^{2}=0.438$ ) in this parameter and includes such predictor variables as $\mathrm{R} 7$, R11, R16 and R19 (Fig. $1 \mathrm{c}$ ).

Best model obtained for the variable LAI_3rings with predictor variables R7, R11, R14, R19, R20 and R22 explains $85.4 \%$ of the variation of LAI on the test plot (Fig. $1 \mathrm{~d}$ ).

Milky ripeness stage: Best regression model for vegetation percentage variable explains $43.2 \%$ of variations in dependent variable (adjusted $R^{2}=0.432$ ) with predictor variables $R 11$ and R20 (Fig. 1 e).

Best obtained regression model explains $44.2 \%$ of the variation of LAI (LAI_3rings) with predictors variables R6, R13, R24, R4 and SAVI2 (Fig. 1 f).

For the variable LAI at all phases of winter wheat development, a range of 0 to 3 was considered, due to the results obtained in the classification of photographs using CAN-EYE. The map for variable LAI_5rings at the phase of tillering (Fig. 1 b) and LAI_3rings at the shooting phase (Fig. $1 \mathrm{~d}$ ) indicate a greater presence of values in a range of 0.0004 to 1.20 , these values agree with those obtained in the classification of photographs. In the phase of milky ripeness, LAI values are higher (1.23 to 2.99 ) as indicated by the map of the variable LAI_3rings (Fig. $1 \mathrm{f}$ ) which corresponds to the results obtained by CAN-EYE.

In the tillering stage of winter wheat development (Fig. $1 \mathrm{a}, \mathrm{b}$ ), low area of surface was covered by vegetation according to the vegetation percentage map, due to the presence of bare soil that has not been occupied by the crop yet. This affected modelling and resulted in low prediction ability of acquired models. 


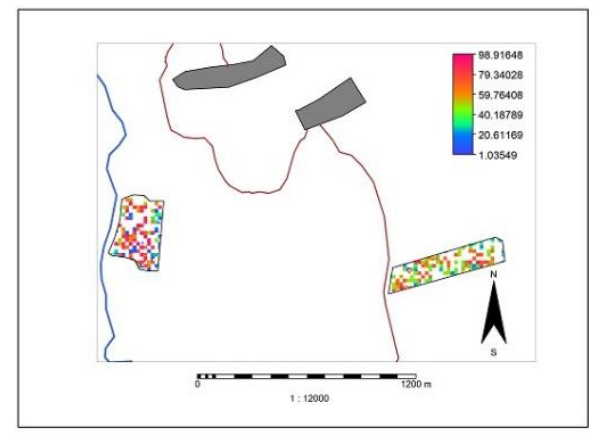

a)

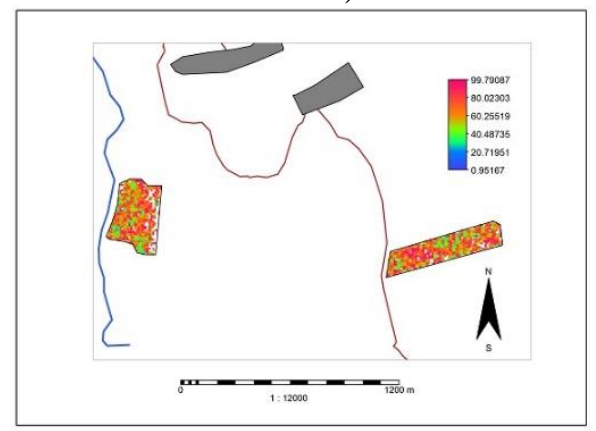

c)

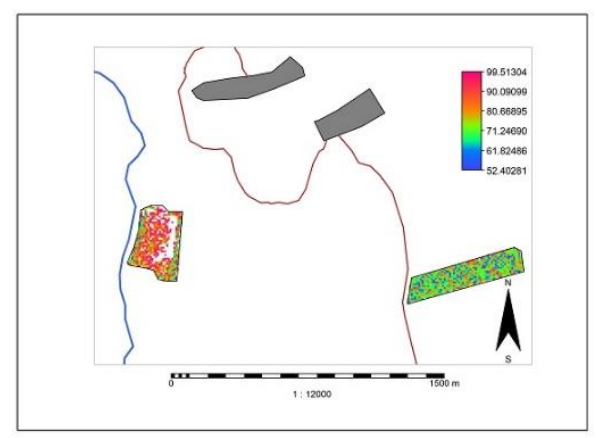

e)

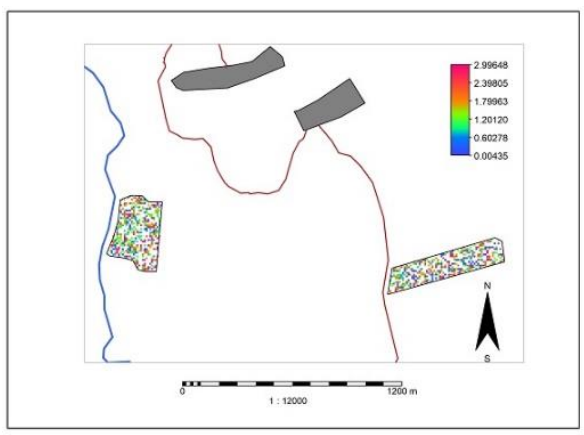

b)

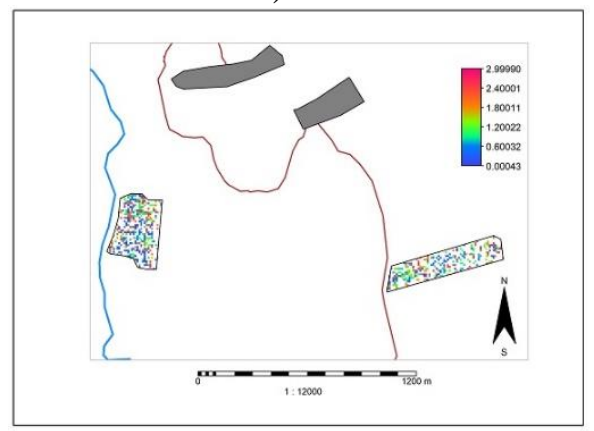

d)

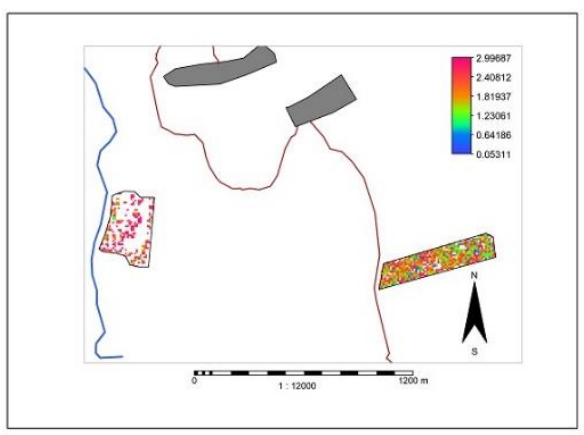

f)

Fig. 1. Maps of vegetation percentage (a, c, e) and LAI (b, d, f) at tillering stage (a, b), shooting stage $(c, d)$ and milky ripeness (e, f) (white color inside test fields corresponds to the areas where models fail (produce negative or too high values))

According to the map for the vegetation percentage (Fig. $1 \mathrm{~d}$ ), at the shooting phase of winter wheat, greater area of surface was covered by vegetation $(60.25-99.79 \%)$, since in this period the crop reaches its highest vegetative development before ripening.

During the milky ripeness stage, the vegetation percentage varies from 71.24 to $99.51 \%$ (Fig. 1 e), because the crop is at the final phase of its cycle. 


\section{Conclusion}

To sum up, according to the results obtained on the basis of ground-truth data, at each stage of winter wheat development the prediction accuracy of the models for determining the percentage of vegetation stayed at $33-43 \%$ with the highest accuracy at the stages of milky ripeness and shooting. As to LAI, the highest accuracy (85\%) was obtained for shooting stage when green biomass of winter wheat was the highest. At other stages the accuracy was below $50 \%$. So, Sentinel-2 data can be successfully used to map LAI at shooting stage of winter wheat. However, this applies only for studied regions and winter wheat.

\section{References}

1. R. Allen, L.S. Pereira, D. Raes, M. Smith, Crop Evapotranspiration-Guidelines for Computing Crop Water Requirements-FAO Irrigation and Drainage Paper, 56, (1998)

2. A.G. Barr, T.A. Black, E.H. Hogg, N. Kljun, K. Morgenstern, Z. Nesic, Agric. For. Meteorol. 126, 237-255 (2004)

3. L. Busetto, S. Casteleyn, C. Granell, M. Pepe, M. Barbieri, M. Campos-Taberner, R. Casa, F. Collivignarelli, R. Confalonieri, A. Crema., et al., J. Sel. Top. Appl. Earth Observ. Remote Sens., 10, 5423-5441 (2017)

4. J. Dietz, D. Hölscher, C. Leuschner, For. Ecol. Manag., 237, 170-178 (2006)

5. B. Duchemin, R. Hadria, S. Erraki, G. Boulet, P. Maisongrande, A. Chehbouni, R. Escadafal, J. Ezzahar, J.C.B. Hoedjes, M.H. Kharrou., et al., Agric. Water Manag. 79, 1-27 (2006)

6. M. Sandmann, J. Graefe, C. Feller, Scientia horticulturae, 156, 113-120 (2013)

7. M. Weiss, F. Baret, CAN_EYE V6.4.91 USER MANUAL (INRA, 2017). URL: https://www6.paca.inra.fr/can-eye/Download

8. M. Martinez, REMOTE PERCEPTION "Fundamentals of Space Remote Sensing", (NATIONAL WATER COMISSION, 2005) URL: https://es.scribd.com/document/365840214/Fundamentos-de-Teledeteccion-Espacial (Last login 12.09.2019). (In Spanish)

9. J. Delegido, J. Verrelst, L. Alonso, J. Moreno, Sensors, 11, 7063-7081 (2011)

10. A.A. Gitelson, A. Viña, V. Ciganda, D. C. Rundquist, T. J. Arkebauer, Geophysical Research Letters, 32, L08403, (2005)

11. J.G.P.W. Clevers, A.A. Gitelson, International Journal of Applied Earth Observation and Geoinformation, 23, 344-351 (2012)

12. Delegido J., Verrelst J., Rivera J.P., Ruiz-Verdú A., Moreno J. Brown, Int. J. Appl. Earth Obs. Geoinf, 35, 350-358 (2015) 